\title{
Mudanças glaciais recentes e variabilidade climática na ilha Rei George, Antártica
}

\section{Glacial recent changes and climate variability in King George Island, Antarctica}

\author{
Kátia Kellem da Rosa ${ }^{a e}$, Vanessa Luisa Freiberger ${ }^{\text {bf }}$, Rosemary Vieira ${ }^{\text {cg }}$, Cláudia Algayer da \\ Rosa $^{\text {dh }}$, Jefferson Cardia Simões ${ }^{\text {ai }}$
}

\author{
àDepartamento de Geografia, Instituto de Geociências- UFRGS, bUniversidade Federal da Fronteira Sul, 'Departamento de \\ Geografia, Universidade Federal Fluminense, ${ }^{\mathrm{d} E s t a t i ́ s t i c a, ~ U n i v e r s i d a d e ~ F e d e r a l ~ d o ~ R i o ~ G r a n d e ~ d o ~ S u l ~}$ \\ ekatia.rosa@ufrgs.br, ${ }^{\mathrm{f}}$ vanessa_luisa25@hotmail.com, ${ }^{\mathrm{g}}$ rosemaryvieira@id.uff.br, ${ }^{\mathrm{h}}$ claudiaalgayer@gmail.com, \\ ijefferson.simoes@ufrgs.br
}

\begin{abstract}
Resumo
O presente trabalho investiga o comportamento das geleiras que fluem para a enseada Martel, localizadas na Ilha Rei George, Península Antártica. A metodologia compreendeu a análise das séries temporais de imagens de satélite para análise da retração glacial e resposta à variabilidade de temperatura média anual superficial do ar (1960-2010) e dias de precipitação líquida anual ao longo das últimas décadas. Os resultados possibilitaram a elaboração de um mapeamento da retração das geleiras para o período $1979-2011$ e evidenciaram a perda de $13,21 \%$ da área total, destacando-se o período de 1979-2000 com maior retração. Destaca-se que devido ao regime termal, dimensões, espessuras e alto grau de retração das geleiras que fluem para a Enseada Martel respondem rapidamente (décadas) a tendência de aumento da temperatura média superficial do ar e alterações na precipitação. As geleiras Wanda (31\%), Dobrowolski (17\%), Dragão (54\%) e Professor (39\%) mostraram maior percentual de perda de área total no período. Este contínuo monitoramento revela possíveis cenários das alterações nesses ambientes glaciais diante da tendência de aumento da temperatura média superficial do ar e precipitação líquida.
\end{abstract}

Palavras chaves: retração glacial; mudanças climáticas; ilha Rei George.

\begin{abstract}
This study investigates the behavior of the glaciers that flow to the Martel Inlet, located in the King George Island, Antarctica Peninsula. The methodology was based on analysis of the temporal series of satellite data of glacier areas (1979-2011) responding to the variability on annual air superficial temperature (1960-2010) and liquid precipitation days. The results allowed the elaboration of a glacial retreat mapping of the behavior of the glaciers in the period $1979-2011$ and evidenced $13.21 \%$ of the loss area. The largest area loss occurred during 1979-2000. It is important to highlight that due to the thermal regime, dimensions, thickness, and high retraction degree of glaciers that flow to the Martel Inlet to respond quickly (decades) to air superficial temperature increased trend and precipitation changes. The Wanda (31\%), Dobrowolski (17\%), Dragon (54\%) and Professor (39\%) glaciers showed highest percentage of the total area loss in the period. This ongoing monitoring reveals possible scenarios of future alterations on these glacial environments before the tendency of increase in the average air superficial temperature and liquid precipitation.
\end{abstract}

Keywords: glacier retreat; climate change; King George Island.

\section{Introdução}

O Continente Antártico, composto também pela Península Antártica e as ilhas adjacentes é considerado como uma relevante área de sorvedouro de energia que perdem a maior parte desta energia para o espaço, na forma de energia infravermelha, isso porque recebe menor quantidade de sol como radiação curta ao longo do ano. Os fatores que intensificam essa redução de recepção de energia são a alta altitude média do continente e a alta refletância (esta que também é conhecida como albedo, refletindo aproximadamente 85\% da radiação solar incidente). A Antártica tem seu manto de gelo composto por $90 \%$ de gelo e $68 \%$ da água potável do planeta, e pequenas variações no seu volume tem relevância global.

A área de estudo deste trabalho, ilha Rei George, está localizada na costa norte da Península Antártica, sendo umas das regiões mais sensíveis às variações climáticas (Setzer 2006). O aumento da temperatura evidenciado 
nas últimas décadas na área de estudo tem como resultado a perda de área e de volume das geleiras. A retração de uma geleira pode produzir impactos regionais e pode ser um fator sinalizador de oscilações climáticas.

Ao longo desse artigo objetiva-se investigar a relação entre os dados anuais de temperatura média superficial do ar e do grau de retração das geleiras da área de estudo. Este estudo pode auxiliar na compreensão das consequências das mudanças climáticas no padrão de retração de geleiras localizadas na região marítima antártica. Com o processo de retração das geleiras torna indispensável o monitoramento da dinâmica global, hidrológica e sedimentar nos ambientes glaciais.

\section{2. Área de estudo}

A enseada Martel localiza-se na baía do Almirantado situada na parte central da Ilha Rei George (figuras 1 e 2). Essa ilha faz parte do Arquipélago das Shetland do Sul, situado $130 \mathrm{~km}$ a noroeste da Península Antártica (Arigony-Neto 2001).

A ilha Rei George possui campos geotérmicos modernos e mantos volcanoclásticos com actividade hidrotermal recente. Ainda que a ilha Rei George não possua atividade vulcânica moderna, há centros vulcânicos próximos como a ilha Deception. Estes processos vulcânicos podem influenciar os processos de degelo (Birkenmajer 1989, Vergara et al. 1992).

Knap et al. (1996) aponta que as massas de gelo das ilhas Shetland do Sul são particularmente sensíveis às variações climáticas em função de sua posição

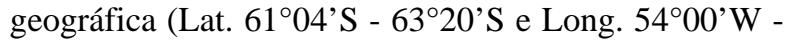

$62^{\circ} 25^{\prime} \mathrm{W}$ ) e da pequena espessura de gelo e por estarem muito próximas do ponto de fusão sob pressão (regime termal basal úmido - geleiras temperadas).

Geleiras temperadas, que são caracterizadas por apresentar toda a massa de gelo próxima ou no ponto de fusão sob pressão, são muito sensíveis a variáveis meteorológicas como a temperatura superficial do ar e a precipitação (Patterson 1994, Vincent 2002, Hock 2005). Geleiras temperadas também podem estar relacionadas com episódios de rápido fluxo de gelo, devido ao deslizamento basal quando tornam-se flutuantes em seu término, como em contato com lagos comparando com geleiras com base em rochas (Meier et al. 1994).

As geleiras Goetel, Ajax, Stenhouse, Dobrowolski e Krak são caracterizadas como geleiras de descarga, enquanto que as geleiras Wanda, Dragão e Professor possuem suas frentes terrestre, ainda que a geleira Wanda desenvolva um sistema lagunar debido a barreira formada por cordões morainicos recessivos. A geleira Dobrowolski possui maior área e apresenta maior aporte visível de sedimentos formando uma pluma sedimentar no setor frontal. As geleiras de maré Goetel, Stenhouse, Krak na área de estudo possuem gradiente superficial acentuado, fluxo relativamente rápido e muitas fendas.

Simões \& Bremer (1995), Bremer (1998), Park et al. (1998), Simões et al. (1999), Braun \& Gossmann (2002) e Rückamp et al. (2011) evidenciaram para períodos entre a década de 1950 a 1995/2000 que geleiras da ilha Rei George estão em processo de retração ligadas diretamente ao aquecimento regional na Península Antártica nas últimas décadas.

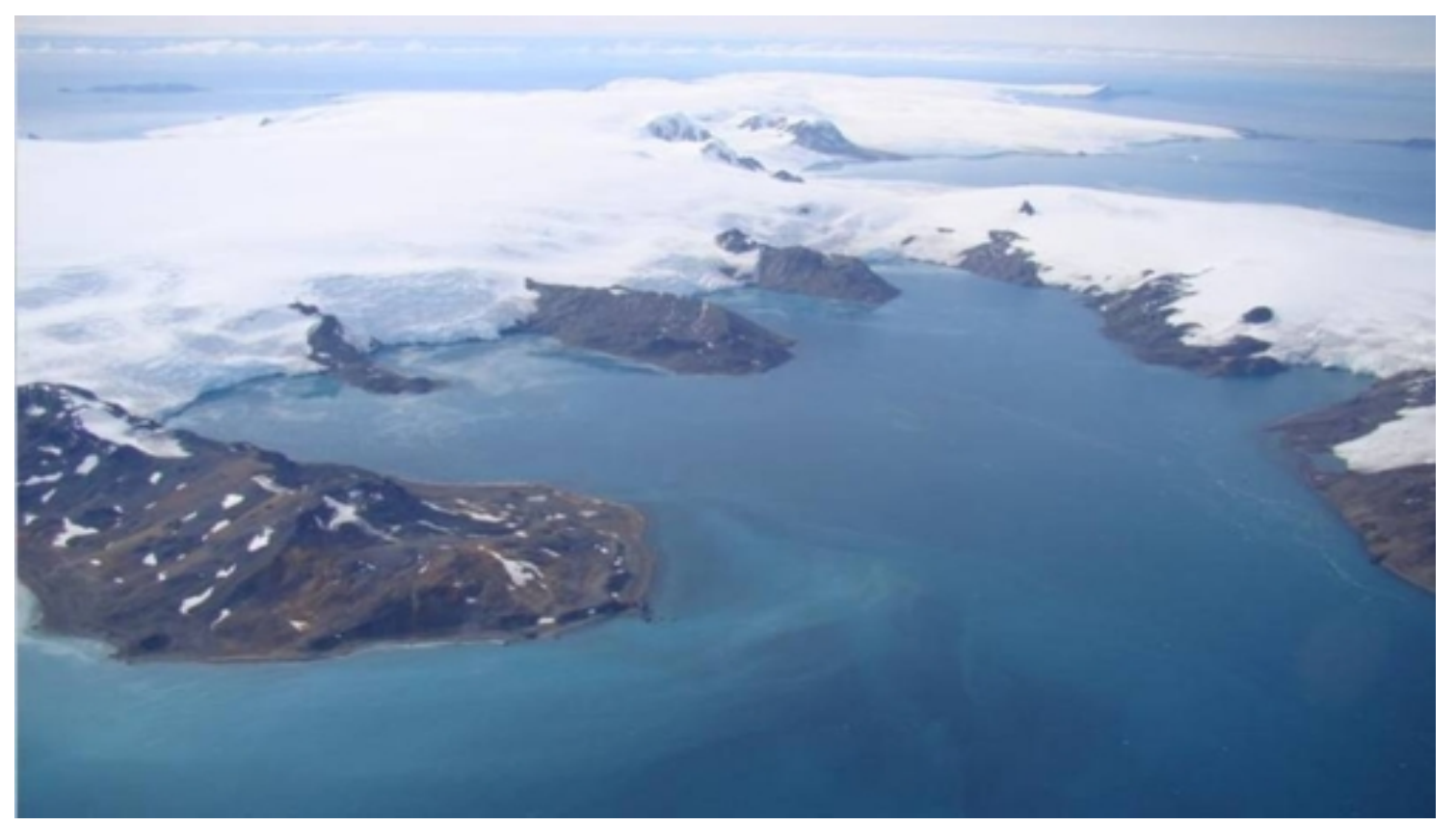

Figura 1: Geleiras que fluem para a Enseada Martel. Fotografia obtida pela equipe da Marinha Brasil. 


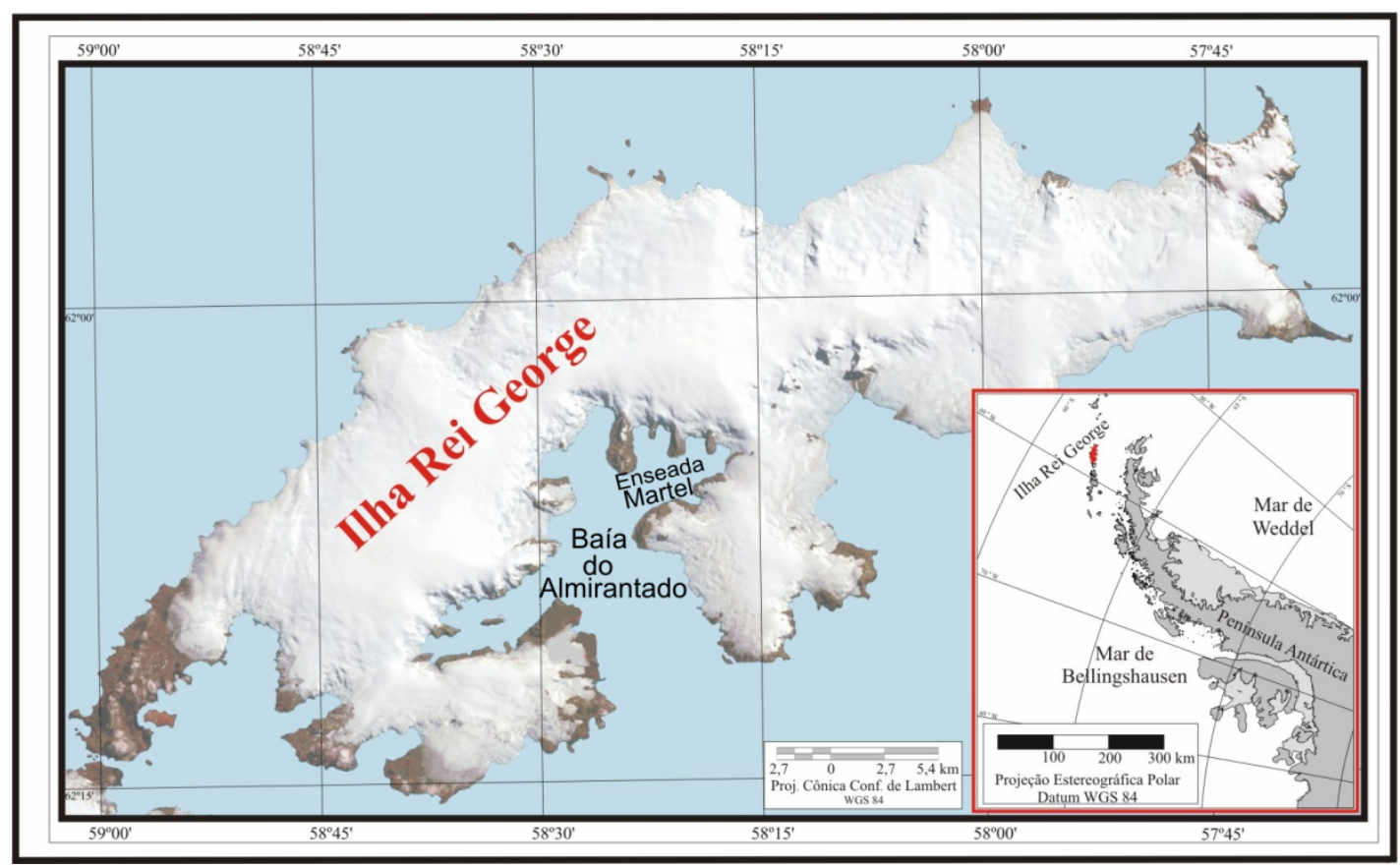

Figura 2: Localização da Enseada Martel na ilha Rei George e na região da Península Antártica.

\section{Metodologia}

Os dados meteorológicos (1960 - 2010) foram disponibilizados pelo INPE (Instituto Nacional de Pesquisas Espaciais) de acordo com a estação meteorológica fixada nas instações da Estação Brasileira Comandante Ferraz (EAFC), localizada na Enseada Martel (62 $2^{\circ} 23^{\prime}$ S 58 $8^{\circ} 27^{\prime}$ O). Os dados meteorológicos do Projeto do INPE foram divulgados na internet por meio da página http://antartica.cptec.inpe.br/ que é disponibilizada pelo CPTEC/INPE (Centro de Previsão de tempo e Estudos Climáticos).

A extensão e a posição de oito geleiras foram quantificadas através da interpretação e mapeamento de imagens de satélite, do SPOT (20 m de resolução espacial, adquiridas em fevereiro de 1988, e em março de 1995 e 2000) e Cosmo-SkyMed (um metro de resolução espacial, adquirida em fevereiro de 2011). A área das geleiras de 1979 foi baseada no estudo de Arigony-Neto (2001) (orthophotomosaic-1979).

Durante as atividades de campo na enseada Martel no período de novembro e dezembro de 2007, janeiro de 2010 e janeiro e fevereiro de 2011 foram adquiridos os dados por GPS (Global Position System) da posição de algumas geleiras.

Os dados de retração (grau de retração anual) das oito geleiras (Wanda, Krak, Ajax, Stenhouse, Dobrowolski, Dragão, Professor, Goetel) foram relacionados aos dados variação anual de dias com precipitação liquida e da variação anual da temperatura média superficial do ar.

\section{Resultados e discussões}

Durante as últimas seis décadas do século 20 a área das geleiras que fluem para a enseada Martel flutuaram marcadamente, como indicado nas figuras 3 e 4. Estas alterações podem estar relacionadas a uma rápida (decadal) resposta das geleiras às mudanças climáticas.

Estudos de Simões et al. (2004), Monaghan et al. (2008), Turner et al. (2009), Blindow et al. (2010) que apontam um aquecimento regional $\left(3^{\circ} \mathrm{C}\right)$ na Península Antártica nas últimas seis décadas. Com relação à tendência da temperatura do ar na área de estudo cabe notar que se consideradas as médias anuais dos últimos 65 anos, houve aquecimento médio de $+0,23^{\circ} \mathrm{C}$ por década (figura 5). Analisando-se a variação de temperatura superficial do ar do verão para o período de 1960 a 2010, observa-se uma tendência de aumento na temperatura $(\mathrm{y}=0,0123 \mathrm{x})+22,67$ (figura 5).

Os períodos entre 1986-1987, 1991-1992 e 1999 tiveram menor número de dias com precipitação de neve. Enquanto que o número de dias com precipitação líquida anual (ocorreram no verão) foi elevado nas décadas analisadas (figura 6).

Estudos de Ferrando et al (2009) relacionam a ocorrência de precipitações sobre a neve na ilha Rei George com o processo de diminuição de área e espessura das geleiras na área de estudo nas últimas décadas. A água provoca fusão da superfície de neve sobre as geleiras, o fluxo de água de degelo penetra nas fendas e se conecta com fluxos englaciais e subglaciais nas geleiras temperadas, o que acelera a velocidade do processo de fusão da geleira no verão e mudanças no balanço de massa das geleiras na ilha Rei George.

Durante a série histórica compreendida nos anos de 1979, 1988, 1995, 2000, 2006 e 2011 a alteração de área das oito geleiras mostram uma tendência a diminuição contínua de área.

O mapa de retração (figura 4) das geleiras que fluem para a Enseada Martel demonstra que no período entre 1979-2011 as geleiras perderam 13,21\% da área total que é de 50,3 km², o que representa uma perda de área 
de gelo de $0,71 \mathrm{~km}^{2}$ (tabela 1 ). A contínua retração destas geleiras encontra-se semelhante ao padrão de retração de muitas geleiras localizadas ao norte do círculo polar Antártico e mesmo na Ilha Rei George, como indicado por Rückamp et al. (2011) para o período 2000 a 2008 (perda de $20 \mathrm{~km}^{2}$ aproximadamente $1,6 \%$ da área total da ilha) e também por estudos de Rosa et al. (2009, 2014) que indicaram uma perda de 4,48 $\mathrm{km}^{2}$ entre $1979-2011$ para a geleira Viéville e 1,35 km² 1956-2000 para a geleira Ecology.

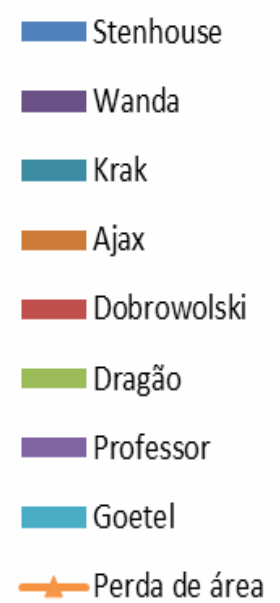

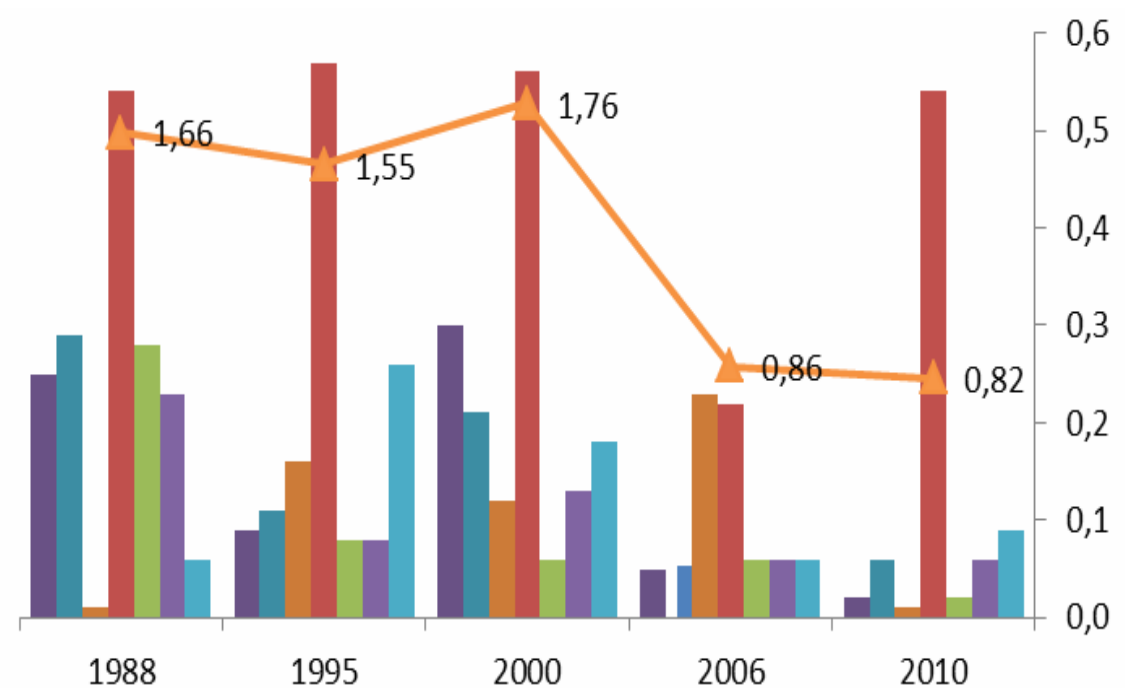

Figura 3: Gráfico ilustra comparativo entre a perda total de área (linha) e a perda de área de cada geleira no período entre $1979-2011$ (barras), dando destaque a geleira Dobrowolski, a qual teve maior perda de área no período entre 1988-2010.

Tabela 1: Taxa de recuo das geleiras de 1979 a 2011. Os limites de área das geleiras foram estabelecidos por Bremer (1998) com base nas características das bacias de drenagem.

\begin{tabular}{|c|c|c|c|c|c|c|c|c|}
\hline Geleiras & Wanda & Krak & Ajax & Stenhouse & Dobrowolski & Dragão & Professor & Goetel \\
\hline Área em $\left(\mathrm{km}^{2}\right) 1979$ & 2,27 & 5,37 & 6,94 & 9,70 & 14,07 & 0,91 & 1,41 & 9,3 \\
\hline Área Perdida $\left(\mathrm{km}^{2}\right)$ e \% & 0,25 & 0,29 & 0,01 & 0,00 & 0,54 & 0,28 & 0,23 & 0,06 \\
\hline $1979-88$ & $(11 \%)$ & $(5,4 \%)$ & $(0,1 \%)$ & $(0 \%)$ & $(3,8 \%)$ & $(30,8 \%)$ & $(16,3 \%)$ & $(0,6 \%)$ \\
\hline Área Perdida $\left(\mathrm{km}^{2}\right)$ e \% & 0,09 & 0,11 & 0,16 & 0,20 & 0,57 & 0,08 & 0,08 & 0,26 \\
\hline 1988-95 & $(4 \%)$ & $(2,2 \%)$ & $(1,7 \%)$ & $(2,1 \%)$ & $(4,1 \%)$ & $(8,8 \%)$ & $(5,7 \%)$ & $(2,8 \%)$ \\
\hline Área Perdida $\left(\mathrm{km}^{2}\right)$ e \% & 0,30 & 0,21 & 0,12 & 0,2 & 0,56 & 0,06 & 0,13 & 0,18 \\
\hline 1995-00 & $(13,2 \%)$ & $(3,9 \%)$ & $(1,7 \%)$ & $(2,1 \%)$ & $(4,0 \%)$ & $(6,6 \%)$ & $(9,2 \%)$ & $(1,9 \%)$ \\
\hline Área Perdida $\left(\mathrm{km}^{2}\right)$ e \% & 0,05 & 0,00 & 0,23 & 0,18 & 0,22 & 0,05 & 0,06 & 0,06 \\
\hline $2000-06$ & $(2,2 \%)$ & $(0 \%)$ & $(3,3 \%)$ & $(1,9 \%)$ & $(1,6 \%)$ & $(5,5 \%)$ & $(4,3 \%)$ & $(0,6 \%)$ \\
\hline Área Perdida $\left(\mathrm{km}^{2}\right)$ e \% & 0,02 & 0,06 & 0,01 & 0,02 & 0,54 & 0,02 & 0,06 & 0,09 \\
\hline 2006-11 & $(0,9 \%)$ & $(1,1 \%)$ & $(0,1 \%)$ & $(0,2 \%)$ & $(3,8 \%)$ & $(2,2 \%)$ & $(4,3 \%)$ & $(1 \%)$ \\
\hline Área em $\left(\mathrm{km}^{2}\right)$ e \% 2011 & 1,56 & 5,06 & 6,41 & 9,10 & 11,64 & 0,41 & 0,85 & 8,65 \\
\hline Total Área Perdida (\%) & $31,3 \times 10^{-2}$ & $11,7 \times 10^{-2}$ & $7,7 \times 10^{-2}$ & $6,2 \times 10^{-2}$ & $17,3 \times 10^{-2}$ & $54,9 \times 10^{-2}$ & $39,8 \times 10^{-2}$ & $7,0 \times 10^{-2}$ \\
\hline $\begin{array}{c}\text { Taxa de retração 1979- } \\
1988 \mathrm{~km}^{2} / \text { ano }\end{array}$ & $2,8 \times 10^{-2}$ & $3,2 \times 10^{-2}$ & $0,1 \times 10^{-2}$ & $0,0 \times 10^{-2}$ & $6,0 \times 10^{-2}$ & $3,1 \times 10^{-2}$ & $2,6 \times 10^{-2}$ & $0,7 \times 10^{-2}$ \\
\hline $\begin{array}{c}\text { Taxa de retração 1988- } \\
1995 \mathrm{~km}^{2} / \text { ano }\end{array}$ & $1,3 \times 10^{-2}$ & $4,2 \times 10^{-2}$ & $2,3 \times 10^{-2}$ & $2,9 \times 10^{-2}$ & $8,1 \times 10^{-2}$ & $1,1 \times 10^{-2}$ & $1,1 \times 10^{-2}$ & $3,7 \times 10^{-2}$ \\
\hline $\begin{array}{c}\text { Taxa de retração 1995- } \\
2000 \mathrm{~km}^{2} / \text { ano }\end{array}$ & $6,0 \times 10^{-2}$ & $0,0 \times 10^{-2}$ & $2,4 \times 10^{-2}$ & $4,0 \times 10^{-2}$ & $11,2 \times 10^{-2}$ & $1,2 \times 10^{-2}$ & $1,2 \times 10^{-2}$ & $3,6 \times 10^{-2}$ \\
\hline $\begin{array}{c}\text { Taxa de retração } 2000 \text { - } \\
2006 \mathrm{~km}^{2} / \text { ano }\end{array}$ & $0,8 \times 10^{-2}$ & $0 \times 10^{-2}$ & $3,8 \times 10^{-2}$ & $3,0 \times 10^{-2}$ & $3,7 \times 10^{-2}$ & $0,8 \times 10^{-2}$ & $0,8 \times 10^{-2}$ & $1,0 \times 10^{-2}$ \\
\hline $\begin{array}{c}\text { Taxa de retração 2006- } \\
2011 \mathrm{~km}^{2} / \text { ano }\end{array}$ & $0,4 \times 10^{-2}$ & $1,2 \times 10^{-2}$ & $0,2 \times 10^{-2}$ & $0,4 \times 10^{-2}$ & $10,8 \times 10^{-2}$ & $0,4 \times 10^{-2}$ & $0,4 \times 10^{-2}$ & $1,8 \times 10^{-2}$ \\
\hline $\begin{array}{c}\text { Total taxa de Recuo no } \\
\text { período } 1979-2011 \\
\mathrm{~km}^{2} / \text { ano }\end{array}$ & $2,2 \times 10^{-2}$ & $2,0 \times 10^{-2}$ & $1,6 \times 10^{-2}$ & $1,8 \times 10^{-2}$ & $7,5 \times 10^{-2}$ & $1,5 \times 10^{-2}$ & $1,7 \times 10^{-2}$ & $2,0 \times 10^{-2}$ \\
\hline
\end{tabular}

No período de 1979 a 1988 a taxa de retração da geleira Dobrowolski foi de $6,0 \times 10^{-2} \mathrm{~km} / \mathrm{ano}$, entre 1988 a 1995 foi de $8,1 \times 10^{-2} \mathrm{~km} / \mathrm{ano}$, entre 1995 a 2000 foi de $11,2 \times 10^{-2} \mathrm{~km} / \mathrm{ano}$, entre 2000 a 2006 foi de 3,7 $\mathrm{x} 10^{-2} \mathrm{~km} / \mathrm{ano}$ e entre 2006 a 2011 obteve uma taxa de $10,8 \times 10^{-2} \mathrm{~km} / \mathrm{ano}$. A geleira Dobrowolski é uma geleira de descarga que possui maior área $\left(14,07 \mathrm{~m}^{2}\right)$ em relação às outras e que apresentou maior taxa de recuo frontal $\left(7,5 \times 10^{-2} \mathrm{~km}^{2} / \mathrm{ano}\right)$ no período analisado (figuras 3 e 4). Esta geleira, comparativamente às demais, apresenta alta deposição de sedimentos no ambiente glaciomarinho (Rosa et al. 2012).

O comportamento de contínua taxa de retração da geleira Dobrowolski reflete a tendência de aumento de temperatura média anual superficial do ar no período. $\mathrm{Na}$ medição de 2006 revelou uma menor taxa de retração (0,03 km²/ano) respondendo a um número maior de dias com precipitação na forma de neve 
comparativamente ao de dias com precipitação líquida, assim como diminuição das temperaturas médias anuais no verão e inverno no início da década de 2000 (figura 7).

As geleiras Stenhouse, Krak, Ajax e Goetel, ambas de descarga (figura 7), apresentaram comportamentos semelhantes. No período correspondente à década de 80 até início da década de 1990 a alta porcentagem de perda de área destas geleiras acompanhou o elevado número de dias com precipitação líquida no período e aos períodos consecutivos de anos com temperaturas médias maiores, tanto no verão como no inverno (figura 7).

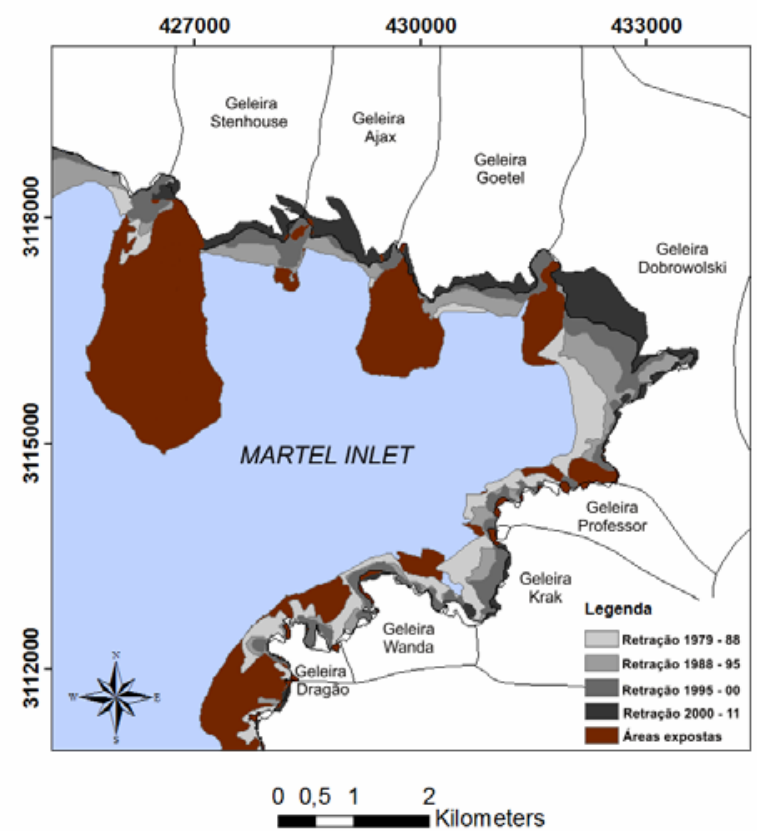

Figura 4: Mapa de retração glacial da extensão das geleiras na Enseada Martel. Os limites de área das geleiras foram estabelecidos por Bremer (1998).

No final da década de 1990 a resposta à diminuição de dias com precipitação líquida e aumento de dias com neve anual no período, podem ter atenuado a taxa de retração destas geleiras, com exceção da geleira Ajax que refletiu a tendência de aumento de temperatura. A taxa de retração menor na década seguinte revela uma provável influência da menor ocorrência de dias com precipitação líquida no início da década de 2000, anos com maior número de dias com precipitação de neve e a invernos com temperaturas mais baixas. As geleiras Professor e Dragão (comparativamente com menores dimensões) apresentaram altas taxas de retração $\left(3,1 \times 10^{-2} \mathrm{~km} /\right.$ ano e $2,6 \times 10^{-2} \mathrm{~km} /$ ano respectivamente) no período de 1979 1988 comparando com suas áreas totais (figuras 4 e 7 e tabela 1), seguindo a retração em uma menor taxa nas décadas posteriores (tabela 1). Este processo pode estar relacionado às suas características de menores dimensões e um processo contínuo de perda de massa nas décadas anteriores, evidenciadas pelas geoformas deposicionais morâinicas. Com a perda de uma ancoragem (deposicional) no setor frontal após deixarem de possuir condições de maré, ambas geleiras podem ter acelerado o processo de retração no período inicial observado.

A geleira Wanda apresentou uma taxa de retração mais elevada (6,0 x 10 $\left.10^{-2} \mathrm{~km} / \mathrm{ano}\right)$ entre 1995-2000, comparativamente ao período anterior $\left(2,8 \times 10^{-2}\right.$ $\mathrm{km} / \mathrm{ano})$ e o período posterior $\left(0,8 \mathrm{x} 10^{-2} \mathrm{~km} / \mathrm{ano}\right)$ (tabela 1). O comportamento deste período pode ter tido influência da tendência de anos consecutivos anteriores com temperaturas médias anuais de verão e inverno mais acentuadas, e anos com menor quantidade de dias de neve, com destaque em 1999 e com uma continuidade de um número alto de dias com precipitação líquida (figuras 6 e 7).

A geleira Dragão, em virtude de sua pouca área relativa $\left(0,91 \mathrm{~km}^{2}\right)$ e pouca alimentação do fluxo de gelo, apresentou nas últimas décadas resultados de retração que condizem com condições de gelo estagnado, ou seja, ausência de fluxo de gelo no período.

Os dados de retração evidenciados corroboram com estudos anteriores sobre estas geleiras para o período entre 1979 a 2000 (Simões \& Bremer 1995, Bremer 1998, Park et al. 1998, Simões et al. 1999, Braun \& Gossmann 2002).

No período mais recente, correspondente a década de 2000, a temperatura média no inverno comportou-se sem elevações significativas e o comportamento das geleiras Krak, Ajax e Goetel não se alterou, apresentando uma taxa de retração maior que na década anterior.

As geleiras que fluem suas frentes para o mar (geleiras de maré, como a Ajax, Stenshouse, Krak, Dobrowolski e Goetel) possuem a dinâmica associada à ação marinha e demonstram em alguns casos apresentar comportamentos diferenciados em relação às flutuações das variáveis meteorológicas, como a temperatura média superficial do ar.

As geleiras Stenhouse, Ajax, Dobrowolski e Goetel estão localizadas em uma área de embasamento rochoso topograficamente mais íngreme, fluindo com mais velocidade, e em contato com a água do mar colapsam, formando growlers. O aumento de perda de área, também pode estar relacionado à perda de uma ancoragem formada por uma topografia rochosa ou por depósitos, como bancos morâinicos na zona submarina.

As geleiras Stenhouse e Ajax podem estar apresentando uma menor taxa de retração anual com o tempo (no período observado) em relação a resposta à tendência de aumento de temperatura média superficial do ar em alguns períodos, e desta forma, podem não responder à variações decadais, mas de um maior intervalo de tempo. No entanto, seria necessária uma análise de balanço de massa para verificar alterações volumétricas nas geleiras. 


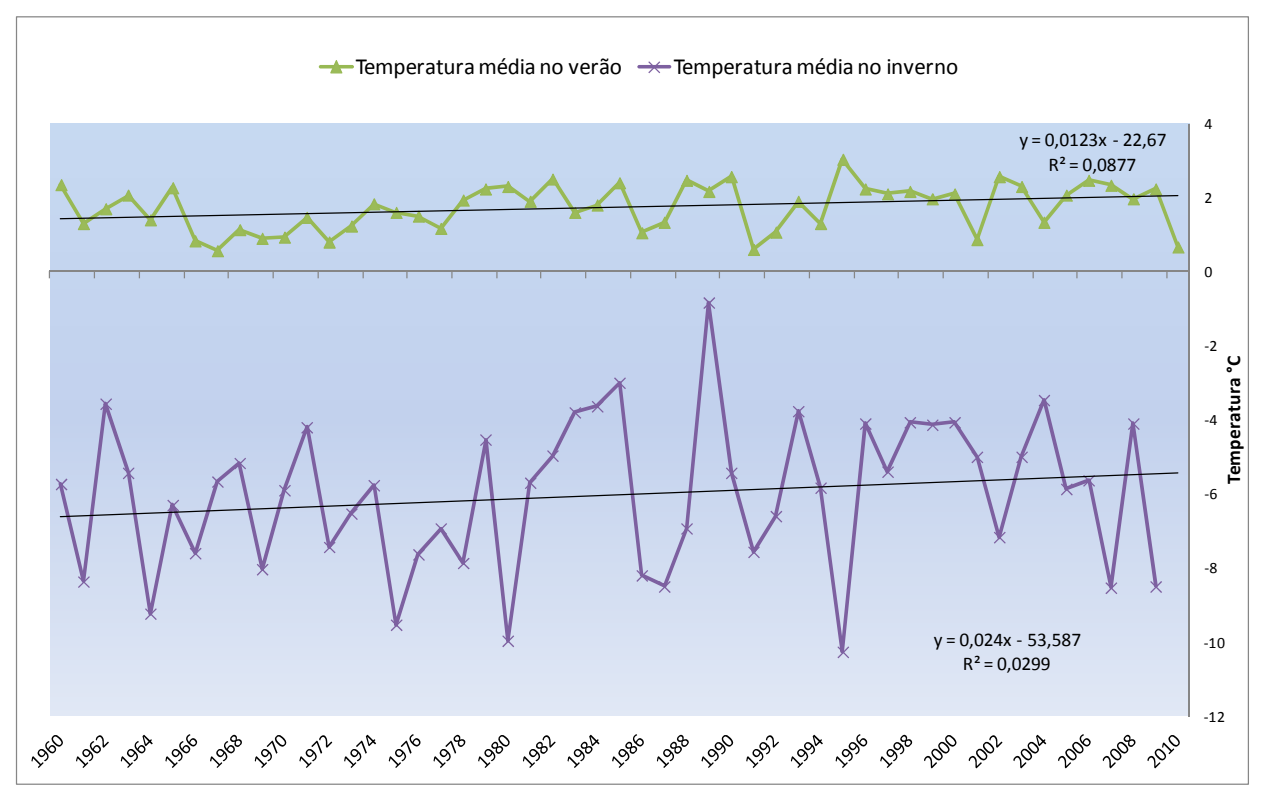

Figura 5: Variação e análise de tendência da temperatura média superficial do ar anual no inverno (linha roxa) e verão (linha verde) do ano de 1960 à 2010 e desvios dos dados anuais em relação às médias dos dados de temperatura média anual, no inverno e no verão.

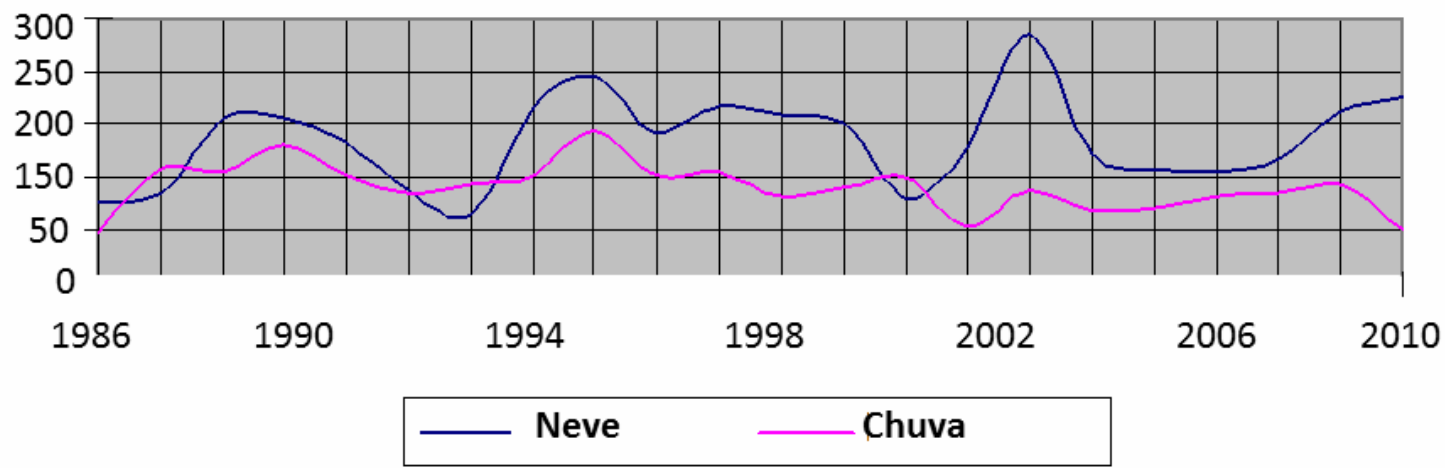

Figura 6: Comparação entre dias com precipitação na forma de neve (linha azul) e precipitação líquida (linha rosa) desde 1986 na ilha Rei George de acordo com dados disponibilizados pelo INPE e coletados na EACF (figura baseada em Ferrando et al. 2009).

Este contínuo monitoramento pode revelar possíveis cenários com a continuidade das alterações.

Verifica-se um importante período de retração glacial de 1979 a 2000, mas seguido pela continuidade da retração, principalmente pelas geleiras Krak, Dobrowolski e Wanda nas décadas posteriores. Predições do aquecimento global de acordo com o IPCC (2013) evidenciam uma provável tendência a uma continuidade do aumento de temperatura média superficial do ar e desta forma também pode estar relacionada a um aumento de precipitação líquida na região da Península Antártica. Assumindo esta tendência positiva das últimas 6 décadas é possível extrapolar um cenário de decrescimento de área das geleiras na área de estudo, podendo desaparecer em meados do século 21 (Dragão) e até o final do século 21 (Wanda e Professor), ou ainda até meados do século 22 (Dobrowolski-geleira que possui maior área e maior taxa de retração).

As informações adquiridas possibilitam aumentar o conhecimento sobre a dinâmica das geleiras localizadas nesta região Antártica e a geração de cenários sobre o comportamento dinâmico desta região diante das mudanças globais.

\section{Considerações finais}

Os resultados revelam que um marcado aumento de temperatura média anual superficial do ar entre 19602010 e períodos de decrescimento de dias de precipitação na forma de neve e de aumento de dias com precipitação líquida (período analisado entre 1986-2011) provavelmente influencia altos graus retração, principalmente no periodo de 1979-2000, das oito geleiras da área de estudo.

As taxas retração destas geleiras com condições termais com temperaturas perto de $0^{\circ} \mathrm{C}$, pequenas dimensões e espessuras evidencia que estas respondem rapidamente (décadas) a variação climática regional.

As geleiras Wanda, Dobrowolski, Dragão e Professor, comparativamente, apresentaram maior perda de área no período, principalmente por processos de fusão basal e degelo supraglacial. Estes processos geram uma maior descarga de sedimentos para o ambiente glaciomarinho, trazendo assim, mudanças na dinâmica sedimentar da área. 


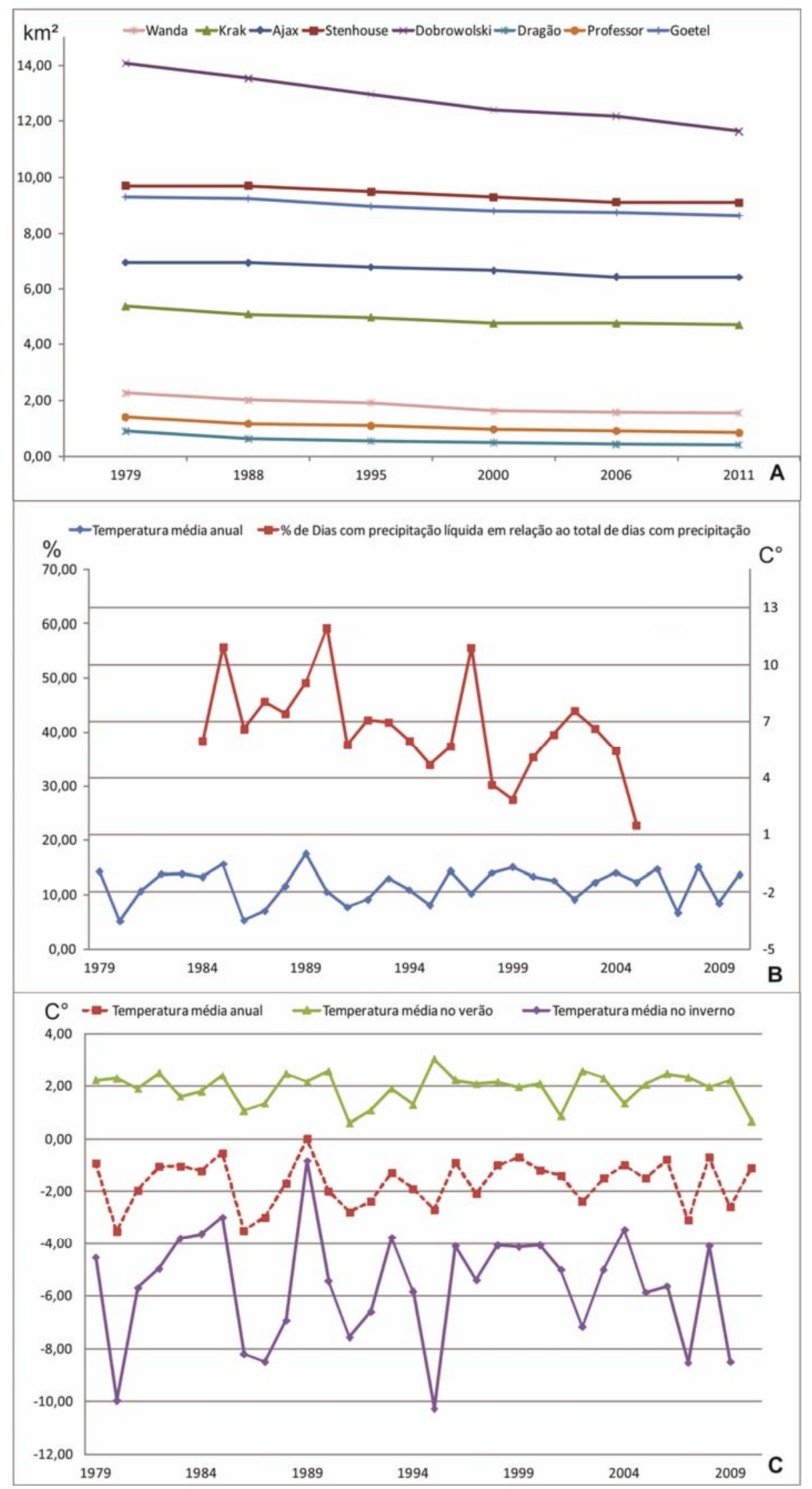

Figura 7: Gráficos mostram (a) evolução da área das oito geleiras que fluem para a enseada Martel demonstrando uma contínua retração e que durante a ultima década a taxa de retração foi menor (b) flutuação dos dados de tempertaura média anual superficial do ar e dos dias com precipitação líquida ao longo dos anos; (c) Dados de temperatura média inverno/verão do ano de 1960 à 2010 e desvios dos dados anuais em relação às médias dos dados de temperatura média anual, no inverno e no verão. Dados de flutuação de temperatura média anual, separando o componente de inverno e os componentes de verão. 
Desta forma, o monitoramento destas geleiras é considerado relevante para estudos sobre o comportamento das geleiras e contribuem para o entendimento dos efeitos das mudanças ambientais e geração de cenários para as geleiras da área de estudos. Essas retrações têm sido ligadas diretamente ao aquecimento regional na Península Antártica nas últimas décadas.

Destaca-se que a ausência de séries temporais de dados de precipitação em milímetros por ano para a área de estudo implica na parcial avaliação da resposta das geleiras às mudanças climáticas no período de tempo considerado. Desta forma, com a obtenção desses dados seria possível realizar uma análise conjunta dos parâmetros de temperatura superficial do ar e de precipitação para ampliar a compreensão das variações temporais na dinâmica do balanço de massa destas geleiras.

\section{Agradecimentos}

Este trabalho foi desenvolvido com o financiamento de recursos provenientes do Conselho Nacional para o Desenvolvimento Científico e Tecnológico (CNPq) (processo 475478/2013-4).

\section{Referências}

Arigony Neto J.N., Bremer U.F., Simões J.C. 2001. Variações nas frentes de gelo da Enseada Martel, Ilha Rei George, Antártica, entre 1956 e 2000. In: Simpósio Brasileiro de Sensoriamento Remoto, 10, Foz do Iguaçu, Anais SBSR, 709-711.

Arigony-Neto J. 2001. Determinação e interpretação de características glaciológicas e geográficas com sistema de informações geográficas na Área Antártica Especialmente Gerenciada Baía do Almirantado, Ilha Rei George, Antártica. Porto Alegre, RS. Dissertação de Mestrado, Universidade Federal do Rio Grande do Sul, 84p.

Birkenmajer K. 1989. A guide to Tertiary geochronology of King George Island, West Antarctica. Polish Polar Research, 10: 555579.

Blindow N., Suckro S.K., Rückamp M., Braun M., Schindler M., Breuer B., Saurer H., Simões J.C., Lange M.A. 2010.Geometry and thermal regime of the King George Island ice cap, Antarctica, from GPR and GPS. Annals of Glaciology, 51 (55): 103-109.

Braun M., Goßmann H. 2002.Glacial changes in the area of Admiralty Bay and Potter Cove, King George Island, Antarctica. In: Beyer, M. \& Boelter M. (ed.): GeoEcology of Terrestrial Antarctic Oases, Springer Verlag, 75-89.

Bremer U.F. 1998. Morfologia e Bacias de Drenagem da Cobertura de Gelo da ilha Rei George, Antártica. Dissertação (Sensoriamento Remoto) - Universidade Federal do Rio Grande do Sul, 117p.

Ferrando F.A., Vieira R., Rosa K.K. 2009. Sobre el calentamiento global en la Isla Rey Jorge: procesos y evidencias en el glaciar Wanda y su entorno. Revista Informaciones Geográficas, 41: 2540.

Hock R. 2005. Glacier melt: a review of processes and their modelling, Progress Physical Geography, 29 (3):362-391.

IPCC, International Panel to Climate Change. 2013. IPCC - Climate Change: The Scientific Basis. Cambridge United Kingdom and New York, NY, USA.

Knap W.H., Oerlemans J., Cadee M. 1996. Climate sensitivity of the ice cap of King George Island, South Shetland Islands, Antarctica. Annals of Glaciology, 23: 154-159.

Meier M.F. 1994. Columbia Glacier during rapid retreat: interactions between glacier flow and iceberg calving dynamics. Proceedings, Workshop on the Calving Rate of West Greenland
Glaciers in Response to Climate Change. N. Reeh (Ed). Danish Polar Center, Copenhagen, $171 \mathrm{p}$.

Monaghan A.J., Bromwich D.H., Chapman W., Comiso J.C. 2008. Recent variability and trends of Antarctic near-surface temperature. Journal of Geophysical Research, 113. doi:10.1029/2007JD009094.

Park B.K., Chang S.K.,Yoon H., Chund H. 1998. Recent retreat of ice cliffs, King George Island, South Shetland Islands, Antarctic Peninsula. Annals of Glaciology, 27: 633-635.

Paterson W.S.B. 1994. The Physics of Glaciers. Elsevier, Oxford, $480 \mathrm{p}$.

Mendes Jr. C.W., Vieira R., Simões J.C. Use of Gis techniques for sediment dynamic analysis of the Martel Inlet, King George Island, South Shetlands. Revista de Geografia (Recife), 29: 6-24.

Vieira R., Ferrando F.A., Simões J.C. 2009. Feições sedimentológicas e geomorfológicas do ambiente de deglaciação das geleiras Wanda e Ecology, ilha Rei George, Antártica. Pesquisas em Geociências (UFRGS. Impresso), 36: 315-326.

Rosa K.K., Simoes C.L., Vieira R., Marotta H., Simoes J.C. 2014. Recent glaciological and geomorphological changes in Kraków Ice Field and Collins Glacier, King George Island, Antarctica. In: XXXIII SCAR Open Science Conference, 2014, Auckland. $1-1$.

Rückamp M., Braun M.; Suckro S.K., Blindow N., 2011. Observed glacial changes on the King George Island ice cap, Antarctica, in the last decade. Global and Planetary Change, 79 (1-2): 99109,doi:10.1016/j.gloplacha.2011.06.009.

Simões J.C., Bremer U.F. 1995. Investigations of King George Island ice cover using ERS-1/SAR and SPOT imagery. Revista SELPER, 11, 1-2: 56-60.

Simões J.C., Bremer U.F. Aquino F.E., Ferron F.E. 1999. Morphology and variations of glacial drainage basins in King George Island icefield, Antarctica. Annals of Glaciology, 29: 220-224.

Simões J.S. Ferron F.A., Bernardo R.T., Aristarain A.J., Stiévenard M., Pourchet M., Delmas R.J. 2004. Ice core study from the King George Island, South Shetlands, Antarctica. Pesquisa Antártica Brasileira, 4: 9-23.

Turner J., Bindschadler R.A., Convey P., Di Prisco G., Fahrbach E., Gutt J., Hodgson D.A., Mayewski P.A., Summerhayes C.P. (eds.). 2009. Antarctic Climate Change and the Environment. Cambridge, UK, Scientific Committee on Antarctic Research, p. 1-32.

Setzer A. 2006. O Brasil e o Meio Ambiente Antártico: Ensino Fundamental e Ensino Médio. 2006. Disponível em: http://portal.mec.gov.br/seb/arquivos/pdf/EnsMed/vol10_meioa mbien1a82.pdf. Acesso em: 10 janeiro de 2014.

Vincent C. 2002. Influence of climate change over the 20th century on four French glacier mass balance. Journal Geophysical Research, 107: 4375, doi:10.1029/2001JD000832, 272, 277. ${ }^{\mathrm{i}}$

Recebido 27 de maio de 2014 Aceito 13 de novembro de 2014 